\title{
Hall-Petch and dislocation strengthening in graded nanostructured steel
}

\author{
Zhang, Xiaodan; Hansen, Niels; Gao, Yukui; Huang, Xiaoxu
}

Published in:

Acta Materialia

Publication date:

2012

Document Version

Early version, also known as pre-print

Link back to DTU Orbit

Citation (APA):

Zhang, X., Hansen, N., Gao, Y., \& Huang, X. (2012). Hall-Petch and dislocation strengthening in graded nanostructured steel. Acta Materialia, 60, 5933-5943.

\section{General rights}

Copyright and moral rights for the publications made accessible in the public portal are retained by the authors and/or other copyright owners and it is a condition of accessing publications that users recognise and abide by the legal requirements associated with these rights.

- Users may download and print one copy of any publication from the public portal for the purpose of private study or research.

- You may not further distribute the material or use it for any profit-making activity or commercial gain

- You may freely distribute the URL identifying the publication in the public portal

If you believe that this document breaches copyright please contact us providing details, and we will remove access to the work immediately and investigate your claim. 


\title{
Hall-Petch and dislocation strengthening in graded
}

\section{nanostructured steel}

\author{
Xiaodan Zhang ${ }^{1}$, Niels Hansen ${ }^{1}$, Yukui $\mathrm{Gao}^{2}$ and Xiaoxu Huang ${ }^{1}$ \\ 1 Danish-Chinese Center for Nanometals, Materials Science and Advanced \\ Characterization-MAC, Department of Wind Energy, Risø Campus, Technical University \\ of Denmark, DK-4000 Roskilde, Denmark \\ ${ }^{2}$ School of Aerospace Engineering and Applied Mechanics, Tongji University, Shanghai \\ 200092, China
}

Key words: shot peening; cold rolling; steel; graded structure; flow stress

\section{Abstract}

The structure and strength of low carbon steel samples have been analyzed after plastic deformation by shot peening and cold rolling. The fine scale surface microstructure caused by shot peening extends to about 50 micrometers below the surface. The structure is graded and subdivided by dislocation boundaries and high angle boundaries showing a clear resemblance to the lamellar structure which evolves during conventional rolling of bulk metallic materials from medium to high strain. As the surface is approached the boundary spacing decreases to about $50 \mathrm{~nm}$ at the surface. In parallel the misorientation angle across boundaries increases to about $65 \%$ of high angle boundaries. The cold rolled steel shows a low hardening rate at high strain and by assuming additive strength contributions from Hall-Petch and dislocation strengthening, the flow stress has been expressed by the relationship $\sigma-\sigma_{0}=k_{2} D_{a v}{ }^{-0.5}$, where $D_{a v}$ is the average spacing between the low and high angle boundaries which subdivide the microstructure, $\sigma_{0}$ is the friction stress and $k_{2}$ is a number which is expressed in terms of structural parameters which have been determined by EBSD. It is found that calculated $k_{2}$ values are in accord with an experimental value of $310 \mathrm{MPa} \mu \mathrm{m}^{0.5}$. In the shot-peened steel the increase in $D_{a v}$ with increasing distance from the surface is transformed into a stress profile based on the $\sigma-D_{a v}$ relationship established for cold-rolled bulk samples. The calculated stress profile is validated by comparison with the experimental profile based on hardness measurements and good agreement is found. This result points to a wider application of the suggested method to derive the local flow stress in a deformed microstructure based on a measurement of the local boundary spacing and the stress-structure relationship for the bulk material in the deformed state.

\section{Introduction}

Please cite this paper as following

$X$ Zhang, N Hansen, Y Gao, X Huang. Hall-Petch and dislocation strengthening in graded nanostructured steel. Acta Materialia 2012; 60: 5933-5943. 
Plastic deformation of metals typically refines the microstructure and increases the strength. At a very large strain the structural scale can reach a nanometer dimension and a very high strength can be obtained. In order to introduce such ultrahigh strain in a bulk sample, many processes have been developed, for example high pressure torsion ${ }^{[1]}$, equal channel angular extrusion ${ }^{[2,3]}$, and accumulative roll bonding ${ }^{[4]}$. However, a hard nanostructure can also be obtained by limiting the plastic deformation to the surface region, for example by shot peening where the surface is bombarded by hard metal balls ${ }^{[5-8]}$. By this process the deformed structure is not uniform, but graded with an increase in fineness as the surface is approached. Such graded structures are also generated when the surface and near surface layers are deformed due to frictional contact ${ }^{[9,10]}$.

A common characteristic of the nanostructured surface layer is its limited extension into the material, typically from a few micrometers ${ }^{[10]}$ to a few tens of micrometers ${ }^{[11]}$. It is therefore difficult to determine the stress and strain profile in the layer, for example to be used in friction models such as by finite element methods ${ }^{[12,13]}$. As a substitute for stress measurements, hardness at increasing depth below the surface has been supplemented by scratch testing ${ }^{[14]}$. As concerns strain profiles, they have been quantified using fiducial markers such as twin and grain boundaries ${ }^{[15,16]}$. However, the spatial resolution of these methods is limited when considering both the fineness of the structure and its limited extension in depth. Also the accuracy of fiducial markers may depend both on the strain level and on a change in chemical composition of the surface layer during deformation.

In order to increase the resolution of the stress estimate in the surface and near surface layer, it has been suggested to supplement the direct techniques with an indirect method where microstructural parameters are quantified by electron microscopy and the stress is calculated based on assumptions with regard to strengthening mechanisms and strengthstructure relationships ${ }^{[12]}$. It is the objective of the present paper to discuss such assumptions, and a shot-peened steel sample is used in the analysis, which is based on a structural and mechanical characterization by scanning electron microscopy (SEM) and by hardness and tensile testing.

The discussion focuses on structural characterization and the strength-structure relationship in samples deformed by cold rolling and by shot peening covering length scales down to $50 \mathrm{~nm}$. In parallel to the analysis of the shot-peened steel sample this study also includes a characterization of the structure and strength of the same steel, which has been cold-rolled to a high strain. Such deformed bulk samples have a lamellar structure like the shot-peened sample and they are used to determine a master curve relating structural parameters to stress values obtained by tensile testing. Such a master curve is used as a guide in the analysis of the stress distribution in the nanostructured graded subsurface layer. This distribution is validated by comparison with hardness data as a function of the distance from the surface. An extrapolation to a length scale of about $10 \mathrm{~nm}$ is also discussed for surfaces plastically deformed by particle bombardment and by friction, respectively.

\section{Experimental}

Please cite this paper as following

$X$ Zhang, N Hansen, Y Gao, X Huang. Hall-Petch and dislocation strengthening in graded nanostructured steel. Acta Materialia 2012; 60: 5933-5943. 
The chemical composition of the steel used in this study was Fe-0.004C-0.44Al-0.017Ni$0.13 \mathrm{Mn}-0.0066 \mathrm{P}$ with an initial average grain size of $40 \mu \mathrm{m}$. High energy shot peening was carried out in air with $\phi 0.8 \mathrm{~mm}$ high carbon steel balls (Fe-0.91C-0.61 Si-0.6Mn$0.021 \mathrm{P}-0.018 \mathrm{~S}$ (wt.\%), HRC 62). The shot velocity was $260-300 \mathrm{~m} / \mathrm{s}$ and the coverage (the area fraction of specimen surface deformed by shots) was $200 \%$ calculated based on the projected area of balls and the weight of balls in the shooting direction in the shooting time. The peening time is 5 minutes. Some oxygen pick-up cannot be excluded but there was no observable effect on the microstructure. The peening angle was $90 \pm 15^{\circ}$ and the peening distance was $20 \mathrm{~cm}$. The shot-peened bar $(\phi 12 \mathrm{~mm})$ was cut into two pieces see Fig. 1, one with a shot-peened surface and the other with an undeformed structure. Microstructural characterization with electron backscattered diffraction (EBSD) and microhardness measurements were carried out in a plane perpendicular to the shotpeened surface. The step size in EBSD was from $20 \mathrm{~nm}$ to $0.2 \mu \mathrm{m}$ increasing with the distance from the surface. The microhardness (Vickers) profile was determined with a load of $50 \mathrm{~g}$ with the holding time of $20 \mathrm{~s}$. Rolled specimens deformed to different strains were prepared from a starting thickness of $9.385 \mathrm{~mm}$ rolled to a final thickness of $\sim 50 \mu \mathrm{m}$ using material cut from the undeformed bottom part of the shot-peened bar, as shown in Fig. 1. The reduction for each pass was around $10 \%$ and the average strain rate was about $0.3 \mathrm{~s}^{-1}$. Rolling reductions were 50,90 and $98.6 \%$, corresponding to true strains, $0.7,2.2$, 4.3. Samples for tensile testing with the tensile axis parallel to the rolling direction were made based on the following standard ${ }^{[17]}: L_{0} \geq 5.65 \sqrt{S_{0}}+\frac{B}{2}$, where $S_{0}$ is the original cross-sectional area of the gauge length, $L_{0}$ the gauge length and $B$ the sample thickness. The width of the gauge was $1 \mathrm{~mm}$ and the total length of the sample was $11.8 \mathrm{~mm}$.

In previous analysis of deformation structures the boundaries subdividing the structure were separated into geometrically necessary boundaries (GNBs) and incidental dislocation boundaries (IDBs) ${ }^{[18,19]}$, and the analysis was based on transmission electron microscopy (TEM) with a spatial and angular resolution of $1 \mathrm{~nm}$ and $0.5^{\circ}$, respectively. In the present study EBSD is introduced with a spatial and angular resolution estimated at $10-20 \mathrm{~nm}$ and $1.5^{\circ}$, respectively. However in order to improve the spatial resolution focused ion beam (FIB) cutting and FIB imaging have been applied in the near surface region. The boundaries were separated based on the misorientation angle into low angle boundaries $\left(<15^{\circ}\right)$ and high angle boundaries $\left(>15^{\circ}\right)$, and the spacing was determined as the average spacing between all boundaries, $\mathrm{D}_{\mathrm{av}}$. In addition, the perpendicular spacing was determined between the lamellar boundaries, $\mathrm{D}^{\mathrm{GNB}}[9]$.

\section{Results}

Fig. 2a shows the evolution of microhardness as a function of strain for rolled samples illustrating a transition from parabolic hardening to linear hardening. No saturation in strength is observed. Fig. $2 b$ shows the microhardness as a function of the distance from the surface for a shot-peened sample. The hardness increases with an increasing rate as the surface is approached and reaches a value of $2.16 \mathrm{GPa}$ at a distance of $110 \mu \mathrm{m}$ from

\section{Please cite this paper as following}

$X$ Zhang, $N$ Hansen, $Y$ Gao, $X$ Huang. Hall-Petch and dislocation strengthening in graded nanostructured steel. Acta Materialia 2012; 60: 5933-5943. 
the surface and a value of $2.74 \mathrm{GPa}$ near the surface. Note that due to the size of the hardness indent the minimum distance from the surface in Fig. $2 b$ is about $25 \mu \mathrm{m}$. In Fig. 3 is shown the relationship between the microhardness and the flow stress $\left(\sigma_{0.2 \%}\right)$ and the ultimate tensile strength (UTS), respectively for the cold-rolled samples, giving the relationships: $\mathrm{Hv}=3.5 \sigma_{0.2}(\mathrm{MPa}), \mathrm{Hv}=3.3 \mathrm{UTS}(\mathrm{MPa})$, in accordance with the relationship typically used, $\sigma=\mathrm{Hv} / 3^{[20]}$. To relate the structural parameters to mechanical properties, EBSD measurements and standard tensile tests were carried out for samples cold rolled to reductions, $50 \%, 90 \%$ and $98.6 \%$, corresponding to true strains, 0.7, 2.2 and 4.3. Microhardness tests were carried out on small pieces cut from the sample after each pass at small strains and after several passes at large strains. No saturation in hardness was found, indicating that the strain at the surface is below 20 which is the saturation strain in pure high pressure torsion (HPT) Ni identified by hardness testing ${ }^{[21]}$.

Figure 4 shows the microstructure at different positions from the surface for the shotpeened sample. The EBSD microstructure is consistent with the microhardness results, indicating that the structure from the shot-peened surface to the inner volume can be divided into three areas with a significant structural difference as shown in Fig 4e: Area A $(0 \sim 110 \mu \mathrm{m}$ from the shot-peened surface $)$ with a well defined lamellar structure with lamellar boundaries parallel to the surface corresponding to the rapid increase in hardness as the surface is approached; Area B $(110 \mu \mathrm{m} \sim 600 \mu \mathrm{m}$ from the shot-peened surface) with a deformed coarse grain structure containing dislocation tangles and dislocation boundaries corresponding to a relatively slow increase in hardness as the surface is approached; Area C (600 $\mu \mathrm{m}$ from the shot-peened surface) which is practically undeformed with a constant hardness and an equiaxed grain size of $40 \mu \mathrm{m}$, corresponding to the initial grain size. The microstructure of the surface layer is shown in Fig. 5, illustrating a minimum perpendicular spacing between lamellar boundaries of about 50 nm.

Fig. 6 shows the lamellar structures in samples which have been cold rolled to true strains of 3.4 and 4.3. Note that a finer and more homogeneous structure evolves as the strain is increased. The structure homogeneity is observed in both the center and the subsurface layers leaving a very narrow surface layer which is affected by friction during rolling. Structural parameters for shot-peened and rolled structures are given in Table 1, showing the same trend as the strain is increased either as the surface is approached or as the rolling reduction is increased: the average boundary spacing decreases and the average boundary misorientation angle increases as does the fraction of high angle boundaries. To further explore the similarity of deformation microstructure introduced by shot peening and by cold rolling, frequency distributions of boundary misorientation angles are shown in Fig. 7 and Fig. 8. Such distributions are characteristic for structures deformed from medium to high strain ${ }^{[22]}$ as they develop into being bimodal with peaks at low angles $(<$ $10^{\circ}$ ) and at high angles (about $50^{\circ}$ ).

\section{Stress-structure relationships}

\section{Please cite this paper as following}

$X$ Zhang, $N$ Hansen, $Y$ Gao, $X$ Huang. Hall-Petch and dislocation strengthening in graded nanostructured steel. Acta Materialia 2012; 60: 5933-5943. 


\subsection{General equations}

The deformed structures after shot-peening are lamellar structures with extended boundaries almost parallel to the surface. Between these boundaries dislocations are stored in low angle boundaries and as randomly distributed dislocations. In previous studies the lamellar structure of deformed bcc and fcc metals have been analyzed as composed of extended geometrically necessary boundaries (GNBs) and interconnecting incidental dislocation boundaries (IDBs) ${ }^{[18,23]}$. The two types of boundaries have been characterized by the perpendicular spacing $\left(\mathrm{D}^{\mathrm{GNB}}\right)$, the misorientation angle $\left(\theta^{\mathrm{IDB}}\right)$, and the surface area per unit volume $\left(S_{v}^{I D B}\right)$ which have been determined by TEM.

The strength-structure relationships for a structure subdivided by GNBs and IDBs have been calculated based on an assumption that the strength contributions from the two types of boundaries are additive ${ }^{[24]}$. The IDBs are assumed to be penetrable to slip and contribute via forest hardening. The GNBs are assumed to be barriers to slip and therefore contribute in the form of grain boundary or Hall-Petch strengthening ${ }^{[23]}$. The flow stress is therefore given by ${ }^{[24]}$ :

$$
\sigma-\sigma_{0}=k_{H P} /\left(2 D^{G N B}\right)^{0.5}+M \alpha G \sqrt{1.5 b \theta_{a v}^{I D B} \cdot S_{v}^{I D B}+\rho_{0}}
$$

Where $k_{H P}$ is the slope of a Hall-Petch plot and the value of $2 D^{G N B}$ represents a randomly measured spacing between the GNBs. The value of $k_{H P}$ can be determined from tensile tests of fully-recrystallized samples, and is estimated at $120 \mathrm{MPa} \mu \mathrm{m}^{0.5}$ determined for an interstitial-free steel ${ }^{[19]}$. The other parameters in Eq. (1) are: the average misorientation angle $\left(\theta_{a v}^{I D B}\right)$ and the area per unit volume of IDBs $\left(S_{v}^{I D B}\right)$, the Burgers vector $b(0.248 \mathrm{~nm})$, the shear modulus $G(77000 \mathrm{MPa})$, the Taylor factor $M$ taken to be $3, \alpha$ a number taken to be $0.24, \sigma_{0}$ the friction stress and $\rho_{0}$ the dislocation density between boundaries which is small and can be neglected. By applying $\mathrm{Eq}$ (1) to $\mathrm{Fe}^{[19]}, \mathrm{Ni}^{[24]}$ and $\mathrm{Al}^{[25,26]}$ cold rolled from low to very high strain showing parabolic and linear hardening good agreement has been found between experimental flow stress values and hardening rates when compared with calculated values based on Eq. (1). In these experiments the structural parameters have been determined by TEM.

As an alternative to Eq. (1), other parameters can be introduced: the average spacing $\left(D_{a v}\right)$ between all boundaries, both GNBs and IDBs; $S_{v}$, the total boundary area per unit volume and $f^{G N B}$, the fraction of GNBs.

$$
\begin{aligned}
& \text { As } S_{v}=S_{v}^{G N B}+S_{v}^{I D B} \\
& S_{v}^{G N B}\left(=1 / D^{G N B}\right)=f^{G N B} S_{v}
\end{aligned}
$$

Please cite this paper as following

$X$ Zhang, N Hansen, Y Gao, X Huang. Hall-Petch and dislocation strengthening in graded nanostructured steel. Acta Materialia 2012; 60: 5933-5943. 


$$
S_{v}^{I D B}=\left(1-f^{G N B}\right) S_{v}
$$

an alternative stress strain relationship is then:

$$
\sigma-\sigma_{0}=k_{H P} \sqrt{\frac{S_{v}}{2} f^{G N B}}+M \alpha G \sqrt{1.5 b \theta_{a v}^{I D B} \cdot S_{v}\left(1-f^{G N B}\right)}
$$

By introducing $S_{v}$ equal to $2 / D_{a v}$, Eq. (5) can be written:

$$
\begin{aligned}
& \sigma-\sigma_{0}=\left\lfloor k_{H P} \sqrt{f^{G N B}}+M \alpha G \sqrt{3 b \theta^{I D B}\left(1-f^{G N B}\right)}\right\rfloor D_{a v}^{-0.5} \\
& \sigma-\sigma_{0}=k_{1} D_{a v}^{-0.5}
\end{aligned}
$$

It has experimentally been found in cold rolled $\mathrm{Fe}$ and $\mathrm{Ni}$ that strengthening due to IDBs is significantly larger than the contribution from $\mathrm{GNBs}^{[19,24]}$, i.e. $k_{1}$ will be higher than $k_{H P}$. Nor will $k_{1}$ be a constant when the strain increases from low to high strain.

As an alternative to TEM the structural parameters can be analyzed by EBSD however with a lower angular and spatial resolution. Quantification of structural parameters especially related to the low angle IDBs is difficult and in more complex structures it can be difficult to distinguish between IDBs and GNBs in the form of interconnecting and lamellar extended boundaries respectively, when applying EBSD. It may therefore be preferable to classify and characterize the boundaries as low angle boundaries $\left(<15^{\circ}\right)$ and high angle boundaries $\left(>15^{\circ}\right)$ although their joint contribution to the flow stress in a deformed structure has not been explored in the same depth as the contributions of IDBs and extended GNBs. The change in classification of deformation-induced boundaries leads to the following stress-structure relationship ${ }^{[27]}$ :

$$
\begin{aligned}
& \sigma-\sigma_{0}=\left\lfloor k_{H P} \sqrt{f^{H A B}}+M \alpha G \sqrt{3 b \theta^{L A B}\left(1-f^{H A B}\right)}\right\rfloor D_{a v}^{-0.5} \\
& \sigma-\sigma_{0}=k_{2} D_{a v}^{-0.5}
\end{aligned}
$$

These equations will be the basis for the analysis in the following.

\subsection{General equations applied to cold rolled steel}

Fig. 9 illustrates the relationship between the flow stress $(0.2 \%$ offset $)$ and the reciprocal square root of the average boundary spacing determined by EBSD. A satisfactory linear relationship is obtained with $k_{1}$ approximately $310 \pm 11 \mathrm{MPa}_{\mu} \mathrm{m}^{0.5}$ and $\sigma_{0}$ about 190 MPa.

$\sigma_{0}$ includes contributions from the friction stress $\left(\sigma_{00}\right)$ of pure iron and a contribution from the solid solution strengthening $\left(\sigma_{s s}\right)$.

\section{Please cite this paper as following}

$X$ Zhang, N Hansen, Y Gao, X Huang. Hall-Petch and dislocation strengthening in graded nanostructured steel. Acta Materialia 2012; 60: 5933-5943. 
$\sigma_{0}=\sigma_{00}+\sigma_{s s}$

where $\sigma_{00}$ is estimated at $50 \mathrm{MPa}{ }^{[19]}$. For the initial recrystallized steel the flow stress $(0.2 \%$ offset $)$ is $195 \mathrm{MPa}$ and the grain size is about $40 \mu \mathrm{m}$. Based on a Hall-Petch slope of $120 \mathrm{MPa} \mu \mathrm{m}^{0.5}{ }^{[19]}$ the grain boundary strength contribution is $19 \mathrm{MPa}$ and $\sigma_{s s}=126$ MPa.

$k_{2}$ in Eq. (8) can be calculated based on EBSD measurements of the average angle of low angle boundaries and the fraction of high angle boundaries $\left(>15^{\circ}\right)$, see Table II. For strain values $0.7,3.4$ and $4.3, k_{2}$ equals 316,421 and $448 \mathrm{MPa}_{\mu \mathrm{m}^{0.5}}$, respectively. These values show an increase in $k_{2}$ with increasing strain and only a reasonable agreement with the experimental value for $k_{2}=310 \mathrm{MPa} \mu \mathrm{m}^{0.5}$. However a cut-off angle of $15^{\circ}$ may not give a correct estimate of the relative contributions from low and high angle boundaries as it has been suggested ${ }^{[27,28]}$ that there exists a critical angle below which the boundary contribution increases with an increase in misorientation angle and above which a dislocation boundary and a high angle boundary show the same resistance. This critical angle has previously ${ }^{[25]}$ been estimated to be of the order of $5^{\circ}$. It is therefore reassuring that relatively good agreement is found between the experimental value for $k_{2}$ $=310 \mathrm{MPa} \mu \mathrm{m}^{0.5}$ and calculated values in Table II for small values of $\theta^{\mathrm{LAB}}$ where $k_{2}$ is in the range $250 \sim 360 \mathrm{MPa} \mu \mathrm{m}^{0.5}$.

The following analysis of the shot-peened surface will therefore be based on the equation:

$\sigma_{(0.2 \% \text { offset })}-190=310 D_{a v}{ }^{-0.5}$

as shown in Fig. 9.

\subsection{General equations applied to shot-peened steel}

The structural analysis of shot-peened steel shows that the spacing between boundaries reaches very small values near the surface of about $50 \mathrm{~nm}$. However as the smallest spacing in the cold-rolled sample is about $200 \mathrm{~nm}$, Eq. (11) has therefore to be extrapolated to larger values of $D_{a v}{ }^{-0.5}$. An approach may be to produce finer bulk structures by applying larger strain and by adding solutes which can reduce dynamic recovery during plastic deformation. This has been tried not only in rolling but also in an experiment ${ }^{[29]}$ where pure $\mathrm{Ni}$ with a small amount of impurities (Ti) has been deformed to a very high strain $\left(\varepsilon_{v M}=100\right)$ by HPT. For HPT Ni the flow stress expressed as $\mathrm{Hv} / 3$ follows Eq. (9) with $k_{2}=296 \mathrm{MPa} \mu \mathrm{m}^{0.5}$ and $\sigma_{0}=320 \mathrm{MPa}$. The numbers are comparable with those obtained for the cold-rolled steel which may not be unexpected due to similarities both in crystallographic structure, shear modulus and characteristics of the deformed microstructure ${ }^{[19,24]}$ supporting an extrapolation of Eq. (11) to about $50 \mathrm{~nm}$

Please cite this paper as following

$X$ Zhang, N Hansen, Y Gao, X Huang. Hall-Petch and dislocation strengthening in graded nanostructured steel. Acta Materialia 2012; 60: 5933-5943. 
allowing the flow stress in shot-peened steel to be calculated as a function of distance from the surface based on Eq. (11).

In order to calculate the stress profile values based on Eq. (11) $D_{a v}$ must be estimated at increasing distances from the surface. The structure is therefore divided into layers with decreasing thickness as the surface is approached and the structure refines ${ }^{[9]}$. This is illustrated in Fig. 10 where the bar length represents the layer thickness and the square the mean spacing in the layer.

The calculated stress profile is shown in Fig. 11 illustrating the very steep gradient in the subsurface region and that the flow stress at the surface may reach about $1360 \mathrm{MPa}, 6-7$ times the flow stress of the undeformed steel in the interior. The calculated stress profile is in Fig. 12 validated by a comparison with the experimental hardness curve (Fig. 2b) transformed into a flow stress profile based on the relationship Hv/3.5 $=\sigma_{(0.2 \%)}$, see Section 3. Fig. 12 illustrates the good agreement between the calculated and experimental stress profiles. However Fig. 12 also shows that the experimental curve is discontinuous at a depth of $25 \mu \mathrm{m}$ which has its cause in the size of the hardness indent being about 25 $\mu \mathrm{m}$. To overcome this uncertainty in the validation the experimental curve is fitted and extrapolated based on the following equation:

$\mathrm{Hv}=4830 \times \mathrm{d}^{-0.17}$

where $d$ represents the distance from the shot-peened surface. At a higher magnification calculated and experimental stress profiles in the top layer are shown in Fig. 13 showing the good agreement between the calculated flow stress $1360 \mathrm{MPa}$ and the extrapolated stress of about $1380 \mathrm{MPa}$. The good agreement near the top surface indicates a continuous evolution in the refinement as the surface layer is approached, i.e. a surface layer with different characteristics due to a pick-up of impurities ${ }^{[10]}$ is not observed. So, the chemical composition of the surface layer was not analyzed. Such a layer is apparently not introduced during shot peening under the present experimental conditions.

\section{Discussion}

\subsection{General}

The microstructural scale in the graded surface layer in shot-peened samples extends from the submicrometer to the nanometer dimension. At the surface the scale has been reduced to about 50nm to be compared with 100-200 nm which typically can be obtained in metals deformed to high and ultrahigh strain by processes such as rolling, wire drawing and extrusion. A further reduction in the structural scale has however been obtained with processing by surface mechanical attrition (SMAT) where the surface is deformed by particle bombardment but where the ball size is large, for example $8 \mathrm{~mm}^{\text {[11] }}$ compared with a size of $0.8 \mathrm{~mm}$ in the present study. Such an increase in the size of the balls increases the impact energy significantly leading to a reduction in the structural scale of the surface and an increase in thickness of the deformed layer. By applying this

\section{Please cite this paper as following}

$X$ Zhang, $N$ Hansen, $Y$ Gao, $X$ Huang. Hall-Petch and dislocation strengthening in graded nanostructured steel. Acta Materialia 2012; 60: 5933-5943. 
technique to deform pure iron ${ }^{[1]}$ it has been possible to reduce the scale of the surface layer to about $10 \mathrm{~nm}$ and to increase the thickness of a nanostructured surface layer to about $15 \mu \mathrm{m}$. A graded surface structure with a similar fineness has been introduced by sliding deformation of copper ${ }^{[9]}$. Data obtained by SMAT deformation of iron and sliding of copper are included in the following discussion together with the present data for shot-peened steel and cold rolled steel in order to cover a structural length scale in a graded structure from a few hundred micrometers to tens of nanometers.

\subsection{Deformation microstructure}

The microstructural characterization of shot-peened and cold rolled samples have a clear resemblance. They are lamellar with extended boundaries almost parallel to the surface and the structure is subdivided by high angle and low angle boundaries with some loose dislocations and dislocation tangles between the boundaries. The similarity between the deformed structures is also demonstrated by applying the scaling hypotheses ${ }^{[22,30]}$ to the distance $\left(\mathrm{D}^{\mathrm{GNB}}\right)$ between the lamellar boundaries measured perpendicular to the surface (see Fig. 14). For comparison data for samples deformed by SMAT and friction are also included in Fig. 14 showing a clear resemblance between the structures formed by the different techniques. In general the deformation microstructure in the shot-peened sample can be characterized as a low-energy structure similar to structures formed by conventional deformation processes ${ }^{[18]}$. A comparison of shot-peened and cold rolled structures however also shows differences. The structural scale in the shot-peened sample is finer and the fraction of high angle boundaries is larger. However, this fraction is somewhat smaller than the fraction of $70 \sim 80 \%$ which can be observed in samples deformed to a very high strain for example by accumulative roll bonding ${ }^{[32]}$, equal channel angular extrusion ${ }^{[33]}$ and high pressure torsion ${ }^{[21]}$ indicating that the strain at the surface in the shot peened sample is high but not ultrahigh.

A comparison of the present shot-peened structures with the surface structures in SMAT and friction samples shows a significantly finer structure in the latter and also a less defined lamellar structure where equiaxed grains and subgrains supplement the lamellae. SMATed and friction samples show a continuous decrease in the boundary spacing as the surface is approached in accordance with the present observation, i.e., in none of the studies is a discontinuous change in the structural evolution observed, as for example, in samples deformed in friction tests where a surface layer can be significantly affected by a pick up of impurities ${ }^{[10]}$.

\subsection{Strengthening mechanisms}

The stress-strain relationship for the cold rolled sample is parabolic at low strain and linear at high strain as has previously been observed in cold-rolled $\mathrm{Ni}^{[24]}$, IF steel ${ }^{[19]}$ and aluminum ${ }^{[26]}$. In these experiments the dominating strengthening mechanisms were suggested to be Hall-Petch and dislocation strengthening being linearly additive. For the shot-peened sample, the same strengthening mechanisms are assumed to operate due to the similarity in the characteristics of the deformed microstructure evolving during cold

\section{Please cite this paper as following}

$X$ Zhang, N Hansen, Y Gao, X Huang. Hall-Petch and dislocation strengthening in graded nanostructured steel. Acta Materialia 2012; 60: 5933-5943. 
rolling and shot peening. However, the stress state is different as significant elastic compressive stresses are introduced in the surface layer during shot peening ${ }^{[6]}$. This can lead to an increase in fatigue strength and fracture resistance and an effect on the strength determined by hardness cannot be excluded. This effect has been analyzed ${ }^{[11]}$ in pure iron deformed by SMAT by characterizing the hardness, the microstrain (measured by Xrays) and the structural parameters in the deformed state and after a heat treatment at $593 \mathrm{~K}$ for 30 minutes. The annealing reduced the mean microstrain whereas the effect on hardness and on grain size was not significant. This led to the conclusion ${ }^{[11]}$ that the dominating strengthening mechanisms in the SMAT sample appear to be dislocation and boundary strengthening. This conclusion indicates that the two strengthening mechanisms operate to the finest structural scale (about $10 \mathrm{~nm}$ ) which is underpinned by a recent analysis of strengthening mechanisms in steel at different structural length scales down to the nanometer dimension ${ }^{[34]}$.

\subsection{Stress-structure relationships}

The stress-structure relationship expressed in Eq. (1) has successfully been applied in an analysis of the stress-strain relationship from low to high strain for cold rolled $\mathrm{Ni}^{[24]}, \mathrm{Al}$ ${ }^{[26]}$ and IF steel ${ }^{[19]}$. In these studies the key structural parameters have been $D^{G N B}$ (the perpendicular spacing between geometrically necessary boundaries), $D^{I D B}$ (the spacing between incidental dislocation boundaries), and $\theta^{I D B}$ (the misorientation angle across IDBs). In this study these parameters have been replaced by $D_{a v}$ (the average spacing between all boundaries, i.e., GNBs and IDBs), $f^{H A B}$ (the fraction of high angle boundaries) and $\theta^{L A B}$ (the misorientation angle across low angle boundaries). This change has led to a change of Eq. (1) to Eq. (8). The consequences of this fundamental change in parameters will be discussed in detail in a forthcoming paper and we shall in the following focus on the relationship:

$\sigma=\sigma_{00}+\sigma_{s s}+k_{2} D_{a v}^{-0.5}$

In applying this equation it must be realized that $k_{2}$ is not a constant (see Eq. (8)) independent of the strain. $k_{2}$ will increase with strain due to an increase in $\theta^{L A B}$ which is approximately proportional to the square root of the strain ${ }^{[35]}$. However at a large strain the increase in $f^{H A B}$ may be balanced by a reduced contribution from low angle boundaries. In accordance with such an evolution it is found in the present study that $k_{2}$ is not strongly dependent on the strain (see Table II).

In applying Eq. (13) with $k_{2}=310 M P a \mu m^{0.5}$ agreement has been found between the experimental and calculated flow stress values for the rolled steel samples (see Section 4.3). However as the finest structural scale in these samples is about $200 \mathrm{~nm}$ an extrapolation to a finer structural scale is desirable to reach the smallest length scale in the shot peened sample. Such an extrapolation is probably the main cause of inaccuracy

\section{Please cite this paper as following}

$X$ Zhang, $N$ Hansen, $Y$ Gao, $X$ Huang. Hall-Petch and dislocation strengthening in graded nanostructured steel. Acta Materialia 2012; 60: 5933-5943. 
in the chosen method. However the recent work for Ni deformed by high pressure torsion (see Section 4.3) gives good confidence in extrapolation of Eq. (13) to a structural scale of about $50 \mathrm{~nm}$ as observed at the surface of the shot-peened sample.

The discussion above is in support of the use of Eq. (13) to calculate the stress profile in the shot-peened sample and good agreement is found with the experimental profiles derived from hardness measurements (see Fig. 12). This agreement validates the stressstructure relationship and its extrapolation to about $50 \mathrm{~nm}$ (see Fig. 13). A further reduction in the structural scale to cover the finest structure in SMAT and friction samples (about $10 \mathrm{~nm}$ ) is for future research requiring mechanical data for bulk samples with structural parameters on the nanoscale. Such data may be obtained for bulk samples by optimizing processing and material parameters. In a supplement to this research a validation of calculated stress profiles on an extreme fine scale will require mechanical test procedures with a high spatial resolution for deformed samples encompassing for example miniature test specimens and nanoindentation. However even nanoindentation may not have the sufficient spatial resolution to quantify the stress gradient in the nanostructured surface layer.

\subsection{Application}

The suggested method to calculate the local stress state in a deformed microstructure has been demonstrated for a surface deformed by particle bombardment. It has however wider applications as it can be used to analyze the stress state in a deformation microstructure independent of its origin based on a measurement of the local boundary spacing and the stress-structure relationship in the bulk material in the deformed state. Also many concrete applications can be suggested for example analysis of surfaces which have been deformed by friction and wear during operation of engineering components such as rollers, rails and gears. The method will also be useful in process optimization in order to tailor the properties of deformed surfaces with special applications in wind turbines, implants and microelectronic components. An important application of the method will be as an input to ongoing development of analytical and numerical 2D and $3 \mathrm{D}$ friction models.

\section{Conclusions}

The structure and strength of steel samples have been analyzed after plastic deformation by shot peening and cold rolling. The conclusions are the following

1. The fine scale graded surface microstructure caused by shot peening extends to about 50 micrometers below the surface. The structure is lamellar and subdivided by dislocation boundaries and high angle boundaries and as the surface is approached the boundary spacing decreases to about $50 \mathrm{~nm}$ at the surface. In parallel the misorientation angle across boundaries increases to a content of $65 \%$ high angle boundaries. The boundary spacing at the surface can be further reduced to about $10 \mathrm{~nm}$ if the ball impact energy is significantly increased as in surface mechanical attrition ${ }^{[11]}$.

\section{Please cite this paper as following}

$X$ Zhang, $N$ Hansen, $Y$ Gao, $X$ Huang. Hall-Petch and dislocation strengthening in graded nanostructured steel. Acta Materialia 2012; 60: 5933-5943. 
2. The surface and subsurface microstructure of the shot-peened steel shows a clear resemblance to the lamellar structures which evolve during conventional rolling of bulk metallic materials from low to high strain. The scaling hypothesis applies to the spacing between the lamellar boundaries and the structure can be characterized as a low energy structure illustrating the universality of grain subdivision during plastic deformation which also appears to apply to graded surface structures caused by high-energy particle bombardment.

3. By assuming additive strength contributions from Hall-Petch and dislocation strengthening, the flow stress of the cold-rolled steel has been expressed by the relationship $\sigma-\sigma_{0}=k_{2} D_{a v}{ }^{-0.5}$, where $D_{a v}$ is the average spacing between the low and high angle boundaries which subdivide the microstructure, $\sigma_{0}$ is the friction stress and $k_{2}$ is a number which is expressed in terms of structural parameters which have been determined by EBSD. It is found that calculated $k_{2}$ values are in

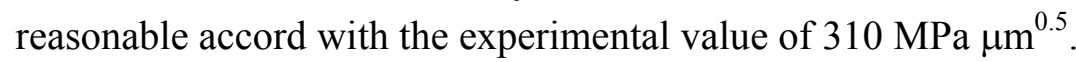

4. The shot-peened steel shows an increase in $D_{a v}$ with increasing distance from the surface. These results are transformed into a stress profile based on the $\sigma-D_{a v}$ relationship established for cold-rolled samples. The calculated stress profile is validated by a comparison with the experimental profile based on hardness measurements and good agreement is found. An extrapolation of the experimental stress profile to the surface shows a very large flow stress of about $1380 \mathrm{MPa}$, in agreement with a calculated flow stress of $1360 \mathrm{MPa}$, about 6-7 times the flow stress of the undeformed steel in the interior. The satisfactory validation is in support of a wider application of the suggested method to derive the local flow stress in a deformed microstructure based on a measurement of local boundary spacing and the stress-structure relationship for the bulk material in the deformed state to underpin analytical and numerical models of materials performance.

\section{Acknowledgements}

The authors (X. Z., N. H. and X. H.) gratefully acknowledge the support from the Danish National Research Foundation and the National Natural Science Foundation of China (Grant No. 50911130230) to the Danish-Chinese Center for Nanometals, within which this work was performed. The authors also thank B. Ralph for his useful comments during the preparation of the manuscript.

\section{References}

[1] Abdulov RZ, Valiev RZ, Krasilnikov NA. J Mater Sci Lett 1990;9:1445.

[2] Segal VM. Mater Sci Eng A 1995;197:157.

[3] Iwahashi Y, Wang J, Horita Z, Nemoto M, Langdon TG. Scripta Mater 1996;35:143.

Please cite this paper as following

$X$ Zhang, N Hansen, Y Gao, X Huang. Hall-Petch and dislocation strengthening in graded nanostructured steel. Acta Materialia 2012; 60: 5933-5943. 
[4] Saito Y, Utsunomiya H, Tsuji N, Sakai T. Acta Mater 1999;47:579.

[5] Lu K, Lu J. Mater Sci Eng. 2004, A375:38.

[6] Dai K, Shaw L. International Journal of Fatigue 2008;30:1398-1408.

[7] Tian JW, Dai K, Villegas JC, Shaw L, Liaw PK, Klarstrom DL, Lrtiz AL. Mater Sci

Eng A 2008;493:176.

[8] Gao YK, Wu XR. Acta Mater 2011;59:3737.

[9] Hughes DA, Hansen N. Physical Review Letters 2001;87:135503.

[10] Rigney DA, Naylor MGS, Divakar R, Ives LK. Mater Sci Eng 1986; 81:409.

[11] Tao NR, Wang ZB, Tong WP, Sui ML, Lu J, Lu K. Acta Mater 2002;50:4603-16.

[12] Hughes DA, Dawson DB, Korellis JS, Weingarten LI. Wear. 1995;181-183:458-68.

[13] Nielsen C, Martins P, Zhang W, Bay N. Steel Research International 2011;82:645650.

[14] Prasad A, Dao M, Suresh S. Acta Mater 2009;57:511.

[15] Heilmann P, Clark WAT, Rigney DA. Acta Metall 1983;31:1293.

[16] Rigney DA, Naylor MGS, Divakar R, Ives LK. Mater Sci Eng 1986; 81:409.

[17] ISO 6892 Metallic materials - Tensile testing at ambient temperature.

[18] Hughes DA, Hansen N. Plastic Deformation Structures, ASM International, Materials Park, OH, 2004, p. 192.

[19] Li BL, Godfrey A, Meng QC, Liu Q, Hansen N. Acta Mater. 2004;52:1069.

[20] Meyers MA, Chawla KK. Mechanical behavior of materials. UK: Cambrige University Press, 2009: 223-224.

[21] Zhang HW, Huang X, Hansen N. Acta Mater 2008;56:5451-65.

[22] Hughes DA, Hansen N. Acta Mater 1997;45:3871.

[23] Kuhlmann-Wilsdorf D, Hansen N. Scripta Metall Mater 1991; 25:1557.

[24] Hughes DA, Hansen N. Acta Mater 2000;48:2985-3004.

[25] Kamikawa N, Huang X, Tsuji N, Hansen N. Acta Mater. 2009;57:4198-4208.

[26] Liu Q, Huang X, Lloyd DJ, Hansen N. Acta Mater 2002;50:3789.

[27] Hansen N. Scripta Mater 2004;51:801-6.

[28] Li JCM. Trans TMS-AIME 1963;227:239.

[29] Zhang HW, Lu K, Pippan R, Huang X, Hansen N. Scripta Mater 2011;65:481-4.

[30] Godfrey A, Hughes DA. Acta Mater 2000;48:1897-1905.

[31] Pantleon W, Hansen N. Acta Mater 2001;49:1479-93.

[32] Kamikawa N, Sakai T, Tsuji N. Acta Mater 2007;55:5873-88.

[33] Mishin OV, Juul Jensen D, Hansen N. Mater Sci Eng A 2003;342:320-8.

[34] Zhang X, Godfrey A, Huang X, Hansen N, Liu Q. Acta Mater 2011;59:3422-30.

[35] Pantleon W, Stoyan D. Acta Mater 2000;48:3005.

Please cite this paper as following

$X$ Zhang, N Hansen, Y Gao, X Huang. Hall-Petch and dislocation strengthening in graded nanostructured steel. Acta Materialia 2012; 60: 5933-5943. 
Table I. Structural parameters for shot-peened samples (SP) at different distances from the surface and for cold-rolled samples (CR) at different strains (EBSD analysis).

\begin{tabular}{|c|c|c|c|c|}
\hline Places or specimens & $\boldsymbol{\theta}_{\mathbf{a v}}(\mathbf{d e g})$ & $\mathbf{D}^{\mathbf{G N B}} \mathbf{( n m )}$ & $\mathbf{D}_{\mathbf{a v}}(\mathbf{n m})$ & $\begin{array}{c}\text { Percentage of } \\
\text { HABs (\%) }\end{array}$ \\
\hline $10-0 \mu$ m_SP & 24.7 & 100 & 115 & 65.1 \\
\hline $20-10 \mu$ m_SP & 21.5 & 158 & 181 & 60.6 \\
\hline $40-20 \mu$ m_SP & 22.1 & 226 & 260 & 55.4 \\
\hline $60-40 \mu$ m_SP & 14.4 & 300 & 360 & 43.2 \\
\hline True strain 0.7_CR & 3.1 & 700 & 700 & 1.8 \\
\hline True strain 3.4_CR & 16.3 & 280 & 343 & 37.2 \\
\hline True strain 4.3_CR & 23.2 & 195 & 242 & 58.1 \\
\hline
\end{tabular}

Table II. Structural parameters and estimation of $k_{2}$ for different cut-off angles in cold rolled samples (see text).

\begin{tabular}{|c|c|c|c|}
\hline Specimens & $\theta_{a v}^{L A B}$ (deg.) & $f^{H A B>15^{\circ}}$ & $k_{2}\left(\mathrm{MPa} \mu \mathrm{m}^{0.5}\right)$ \\
\hline True strain 0.7 CR & 2.3 & 0.02 & 316 \\
\hline True strain 3.4_CR & 4.6 & 0.31 & 421 \\
\hline True strain 4.3 CR & 6 & 0.45 & 448 \\
\hline Specimens & $\theta_{a v}^{L A B}$ (deg.) & $f^{H A B>10^{\circ}}$ & $k_{2}\left(\mathrm{MPa} \mu \mathrm{m}^{0.5}\right)$ \\
\hline True strain $0.7 \_\mathrm{CR}$ & 2.2 & 0.03 & 312 \\
\hline True strain $3.4 \mathrm{CR}$ & 3.9 & 0.38 & 389 \\
\hline True strain $4.3 \_\mathrm{CR}$ & 4.1 & 0.58 & 352 \\
\hline Specimens & $\theta_{a v}^{L A B}$ (deg.) & $f^{H A B>8^{\circ}}$ & $k_{2}\left(\mathrm{MPa} \mu \mathrm{m}^{0.5}\right)$ \\
\hline True strain 0.7 CR & 2.1 & 0.04 & 310 \\
\hline True strain 3.4_CR & 3.1 & 0.44 & 358 \\
\hline True strain $4.3 \_\mathrm{CR}$ & 3.5 & 0.65 & 305 \\
\hline
\end{tabular}

Please cite this paper as following

$X$ Zhang, $N$ Hansen, $Y$ Gao, X Huang. Hall-Petch and dislocation strengthening in graded nanostructured steel. Acta Materialia 2012; 60: 5933-5943. 


\begin{tabular}{|c|c|c|c|}
\hline Specimens & $\theta_{a v}^{L A B}(\mathrm{deg})$. & $f^{\mathrm{HAB}>6^{\circ}}$ & $k_{2}\left(\mathrm{MPa} \mu \mathrm{m}^{0.5}\right)$ \\
\hline True strain 0.7_CR & 2 & 0.06 & 305 \\
\hline True strain 3.4_CR & 2.1 & 0.53 & 315 \\
\hline True strain 4.3_CR & 2.8 & 0.71 & 253 \\
\hline
\end{tabular}

Figures

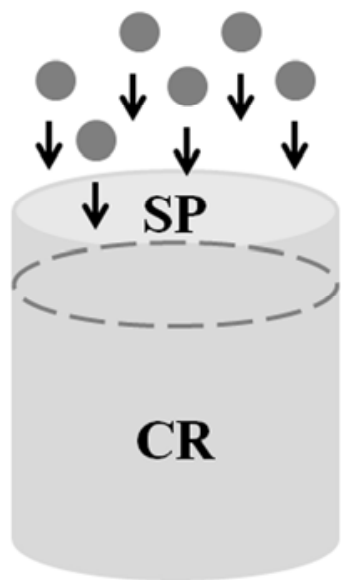

Figure 1. Samples investigated: one with a shot-peened surface and another with an undeformed structure to be cold-rolled.
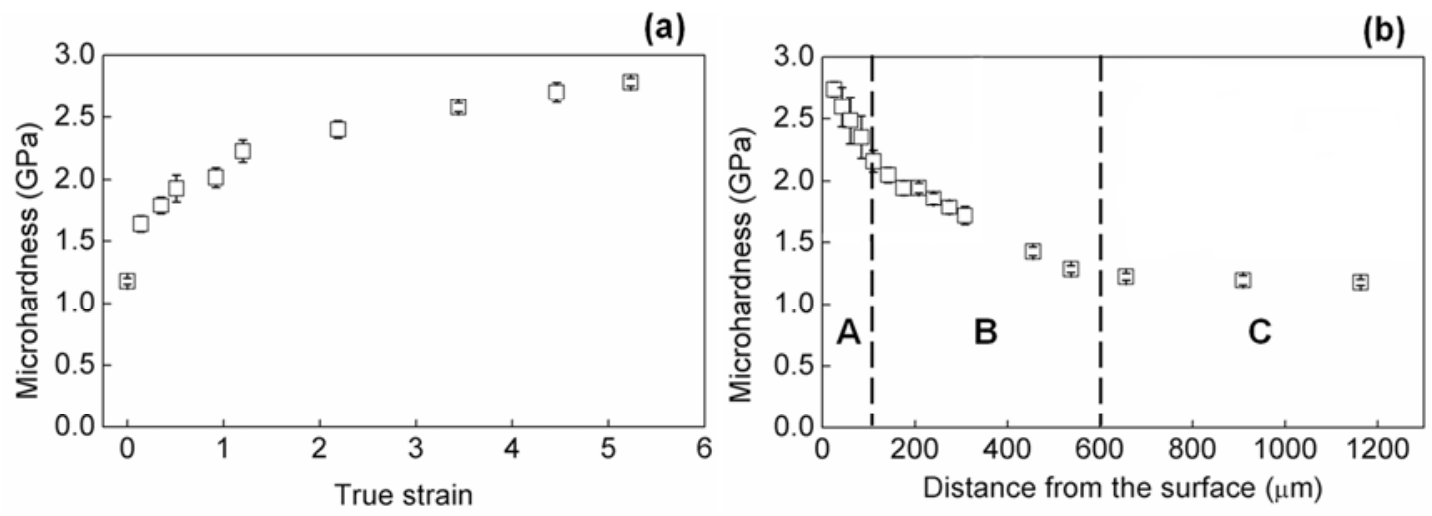

Figure 2. Microhardness as a function of true strain for rolled samples (a) and microhardness as a function of distance from the surface for a shot-peened sample (b). The error bars represent the standard deviation of the hardness data. For the division into areas A, B and C see text and Fig. 4e.

Please cite this paper as following

$X$ Zhang, N Hansen, Y Gao, X Huang. Hall-Petch and dislocation strengthening in graded nanostructured steel. Acta Materialia 2012; 60: 5933-5943. 


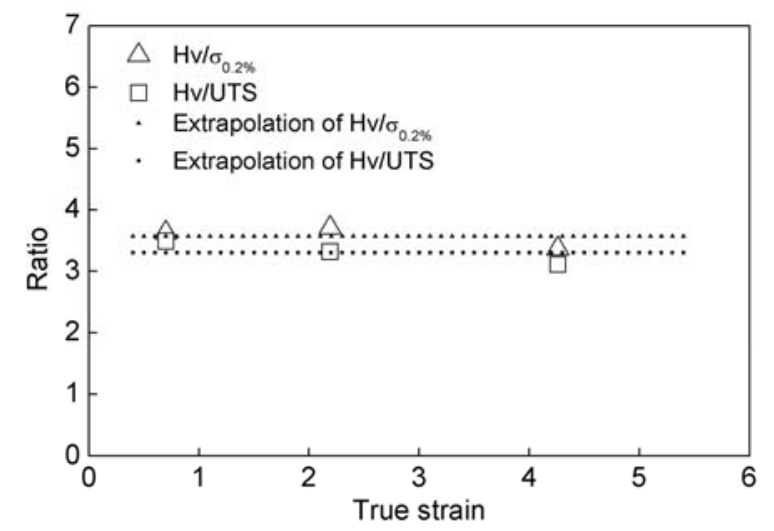

Figure 3. Ratio of Hv to flow stress $(0.2 \%$ offset) and to UTS as a function of true strain for cold rolled samples showing no strain dependency.
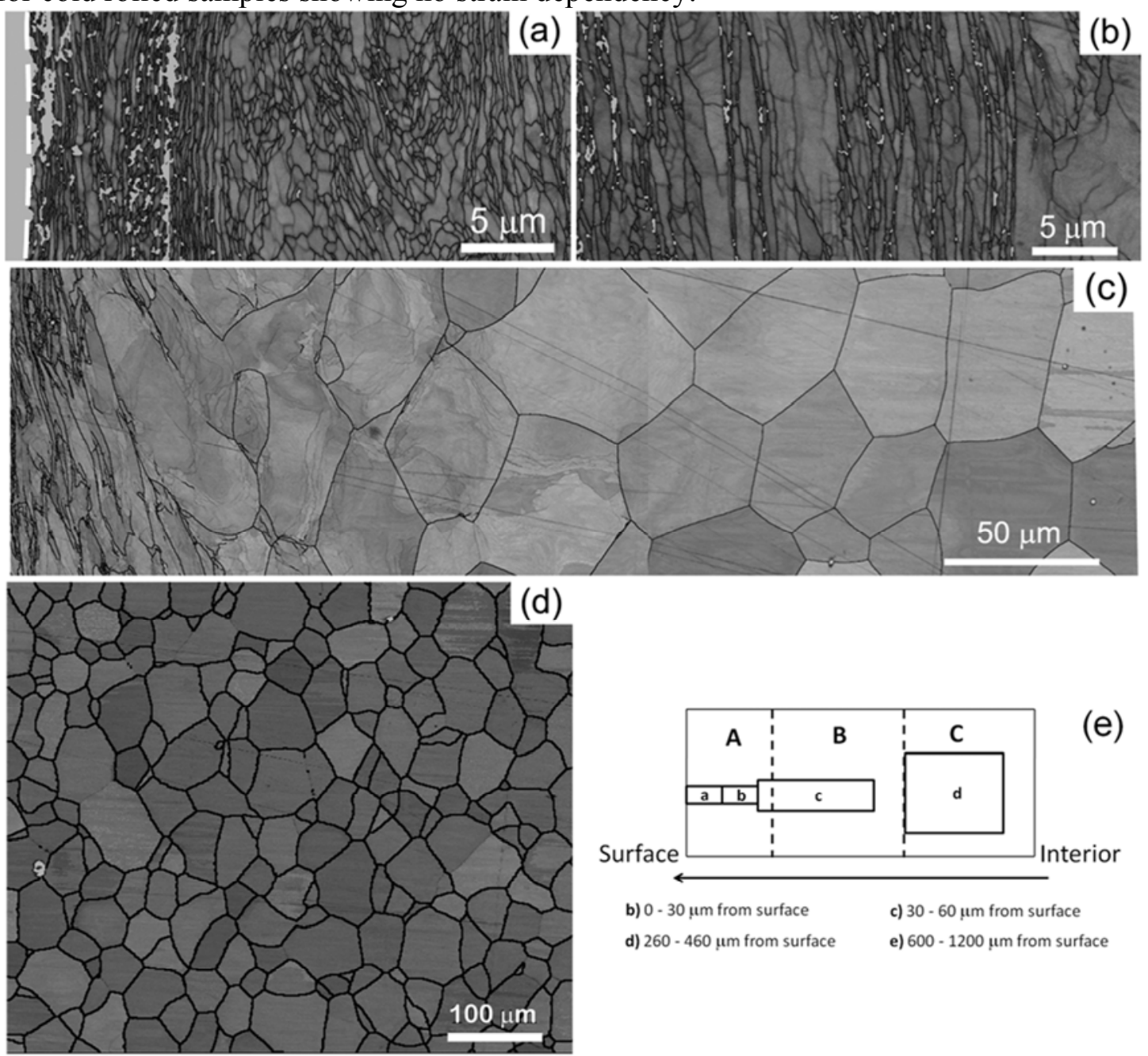

b) 0 - $30 \mu \mathrm{m}$ from surface

c) $30-60 \mu \mathrm{m}$ from surface

d) $260-460 \mu \mathrm{m}$ from surface

e) $600-1200 \mu \mathrm{m}$ from surface

Figure 4. (a) - (d) EBSD microstructure with a band contrast component (Kikuchi pattern quality) corresponding to the location indicated in the schematic illustration (e) showing

Please cite this paper as following

$X$ Zhang, $N$ Hansen, $Y$ Gao, $X$ Huang. Hall-Petch and dislocation strengthening in graded nanostructured steel. Acta Materialia 2012; 60: 5933-5943. 
the locations of EBSD characterization with capital letters A, B and C corresponding to areas marked in Fig 2b. The black lines are high angle boundaries with micorientation angles larger than $15^{\circ}$. The dashed white line shows the position of surface. Zero solution in the microstructure ((a) and (b)) are shown in silver colour, resulting from the overlapping of kikuchi patterns from two subgrains on both sides of one (sub)grain boundary. The scratch lines in Fig. $2 \mathrm{c}$ are grinding traces from sample preparation.

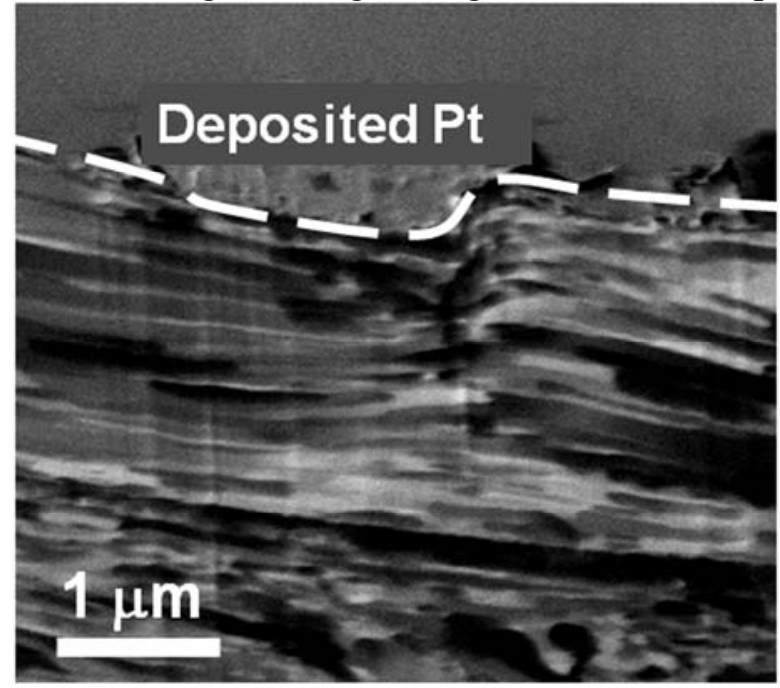

Figure 5. Microstructure of the surface layer in a shot-peened sample illustrating a minimum perpendicular spacing between lamellar boundaries of about $50 \mathrm{~nm}$. The surface (white dashed line) is protected by deposited platinum and the sample has been cut by a focused ion beam (FIB).

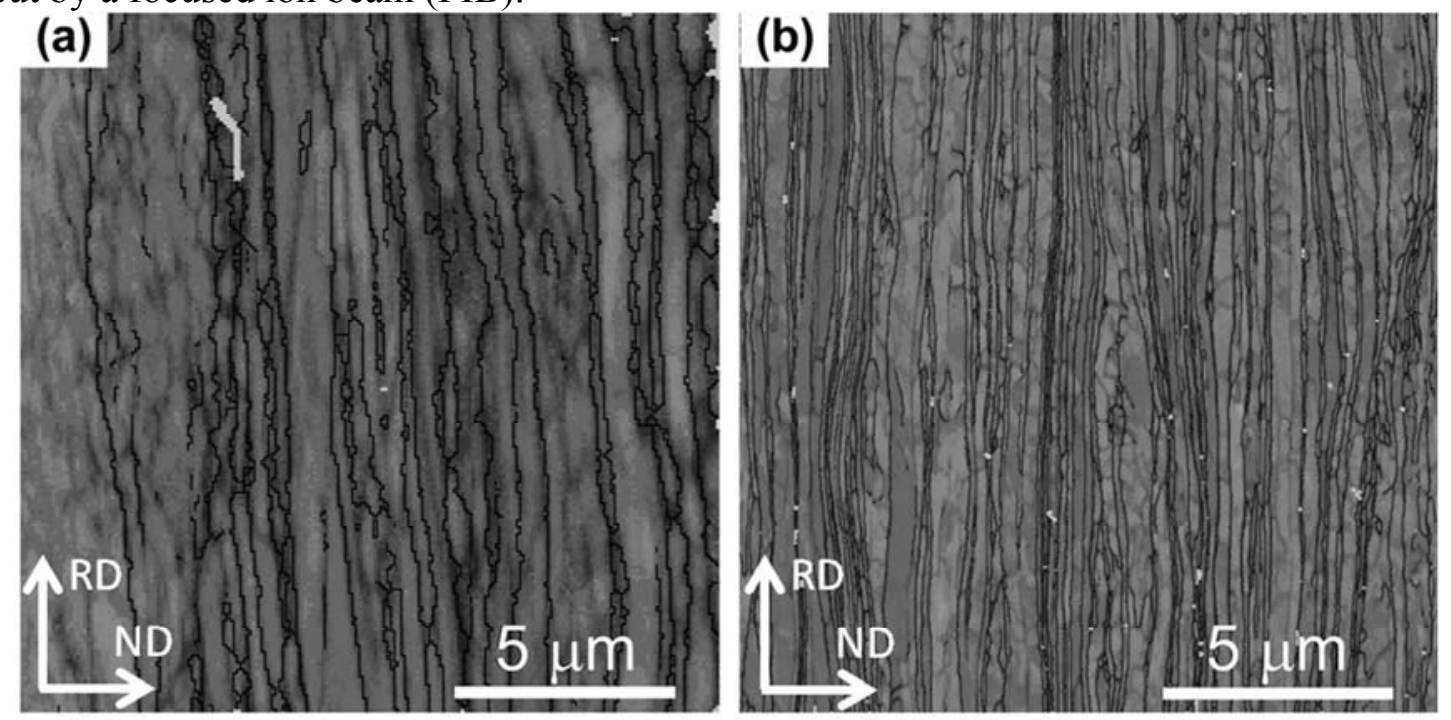

Figure 6. EBSD microstructure close to the center with a band contrast component (Kikuchi pattern quality) of cold rolled specimens at strains of 3.4 (a) and 4.3 (b). The black lines are high angle boundaries with micorientation angles larger than $15^{\circ}$. Zero solution are shown in silver.

\section{Please cite this paper as following}

$X$ Zhang, N Hansen, Y Gao, X Huang. Hall-Petch and dislocation strengthening in graded nanostructured steel. Acta Materialia 2012; 60: 5933-5943. 

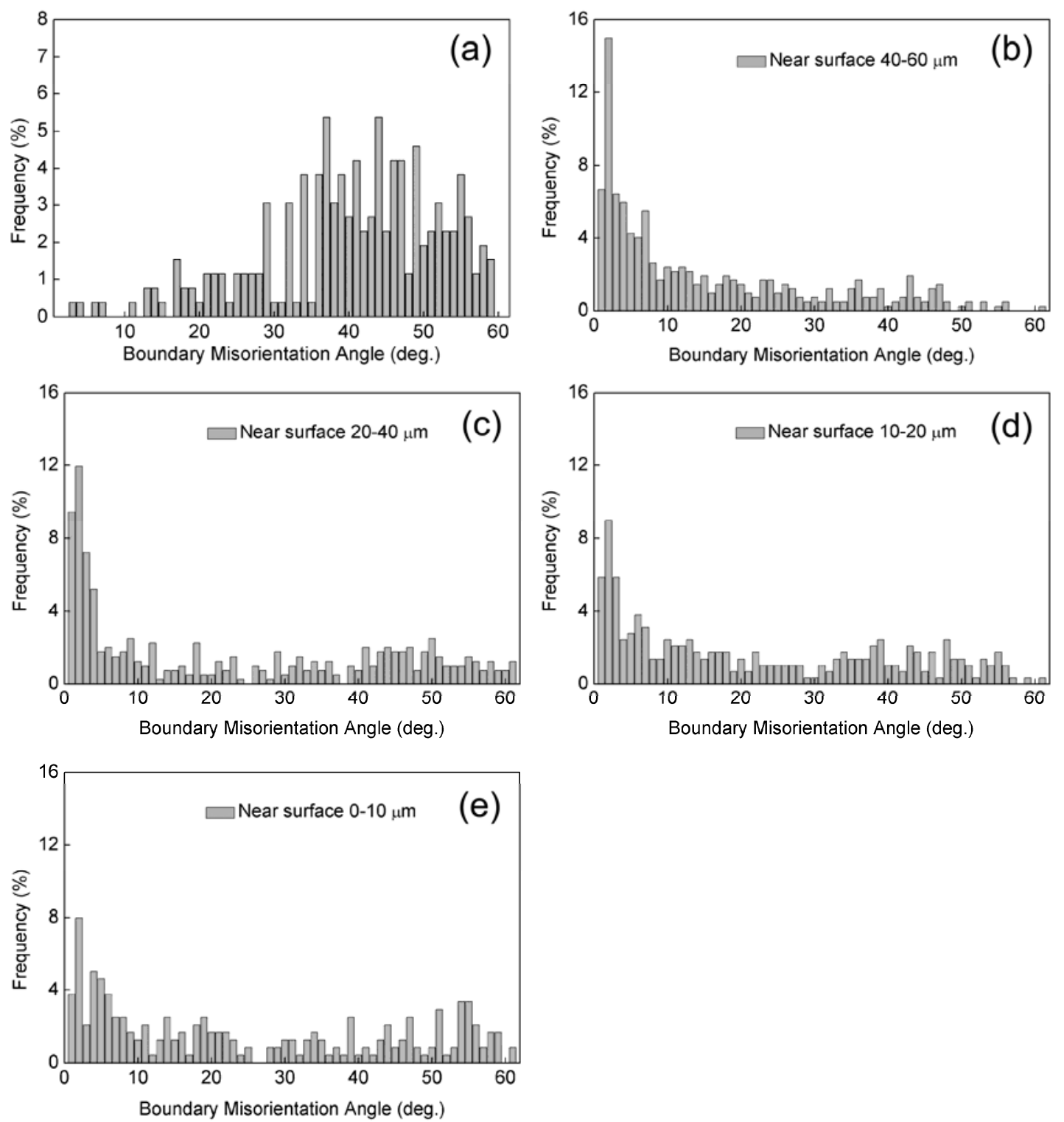

Figure 7. Frequency of grain boundary misorientation angles of the initial recrystallized structure showing a random distribution (a) and frequency of boundary misorientation of areas with different distances to the shot-peened surface: 40-60 $\mu \mathrm{m}(\mathrm{b}), 20-40 \mu \mathrm{m}$ (c), 10 $20 \mu \mathrm{m}(\mathrm{d}), 0-10 \mu \mathrm{m}(\mathrm{e})$.

Please cite this paper as following

$X$ Zhang, N Hansen, Y Gao, X Huang. Hall-Petch and dislocation strengthening in graded nanostructured steel. Acta Materialia 2012; 60: 5933-5943. 

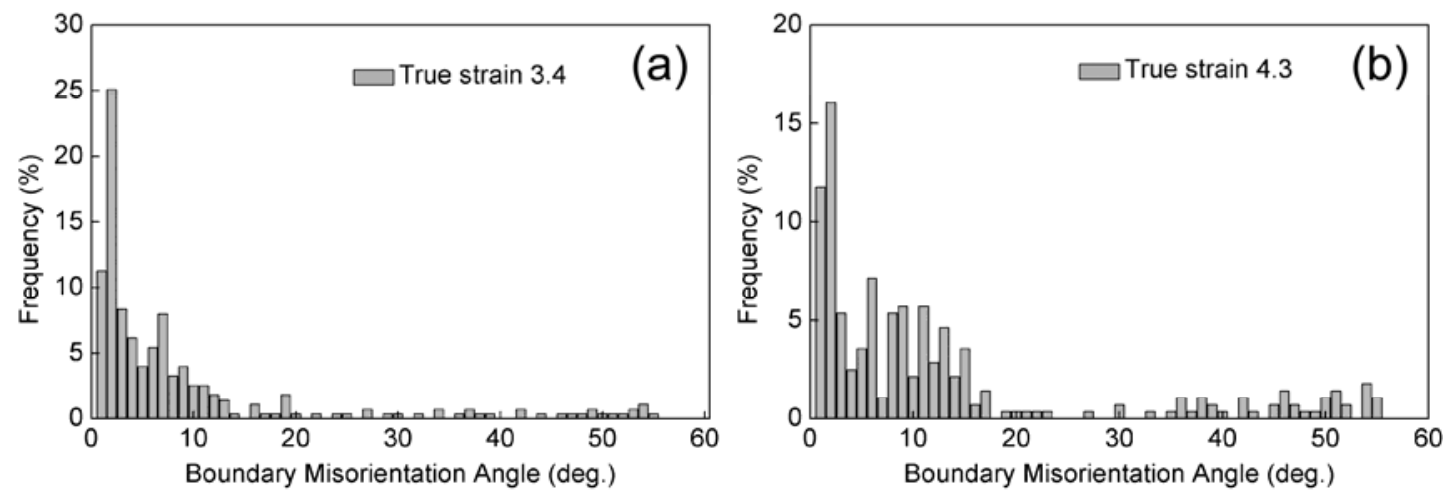

Figure 8. Frequency of boundary misorientation angles of rolled specimens at strains of 3.4 (a) and 4.3 (b).

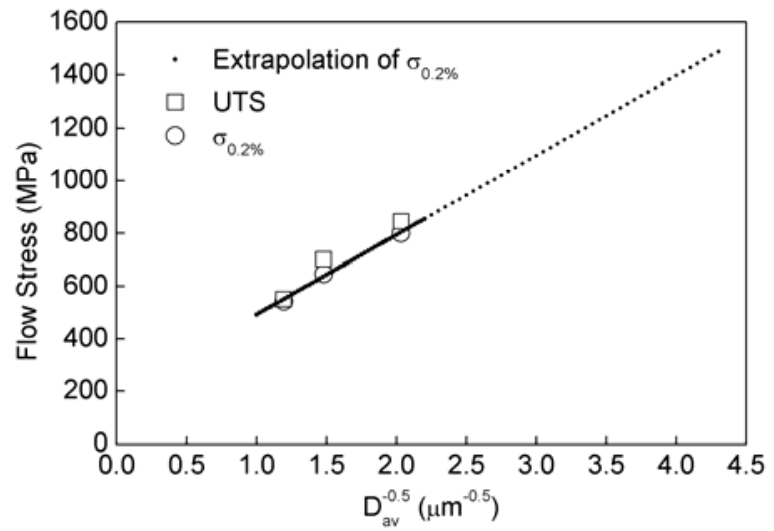

Figure 9 . Flow stress $(0.2 \%$ offset $)$ versus the reciprocal square root of the average boundary spacing for cold rolled samples. The straight line between the experimental values is extrapolated to $D_{a v}{ }^{-0.5}=4.5 \mu m^{-0.5}$ corresponding to $D_{a v}=50 \mathrm{~nm}$ representing the spacing of the surface (see Fig. 5 and text).

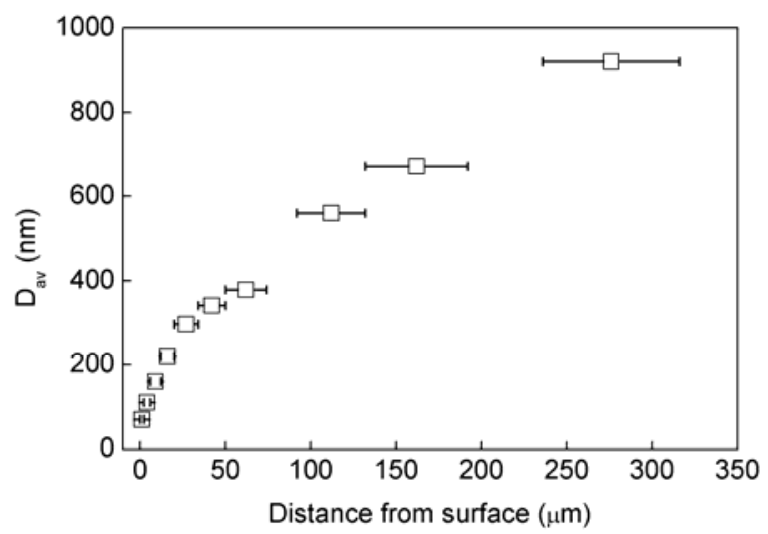

Figure 10. $D_{a v}$ vs Distance from the shot-peened surface.

Please cite this paper as following

$X$ Zhang, N Hansen, Y Gao, X Huang. Hall-Petch and dislocation strengthening in graded nanostructured steel. Acta Materialia 2012; 60: 5933-5943. 


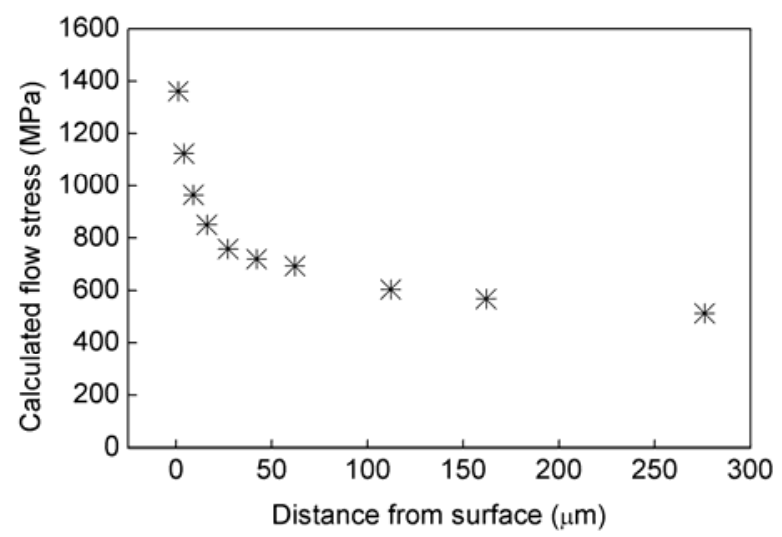

Figure 11. Calcualted flow stress $(0.2 \%$ offset $)$ as a function of distance from the shotpeened surface.

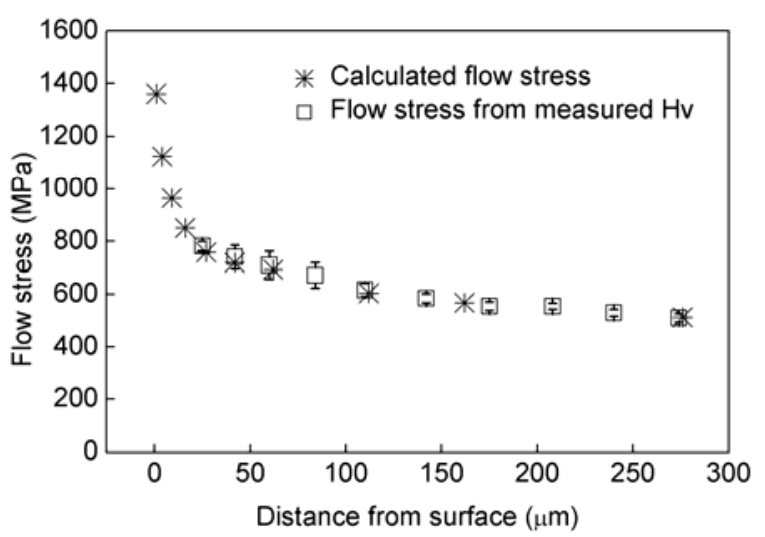

Figure 12. Calculated flow stress ( $0.2 \%$ offset) and flow stress based on microhardness (Hv) data transformed to flow stress using the relationship $\sigma_{0.2 \%}=1 / 3.5 \mathrm{Hv}$ (see Section $3)$. The experimental curve extends to a distance of $25 \mu \mathrm{m}$ from the surface (see text).

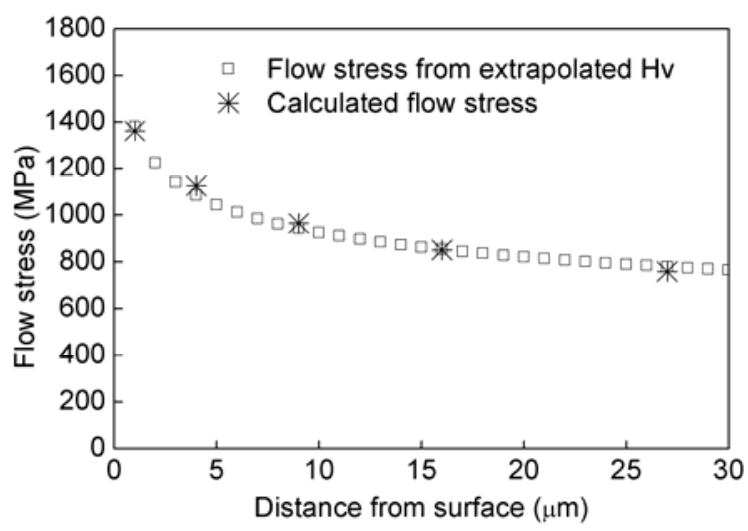

Figure 13. Calcualted flow stress and flow stress from extrapolated microhardness (Hv) (Eq. 12) as a function of distance from the shot-peened surface in the top surface layer extending $25 \mu \mathrm{m}$ into the sample.

\section{Please cite this paper as following}

$X$ Zhang, $N$ Hansen, $Y$ Gao, X Huang. Hall-Petch and dislocation strengthening in graded nanostructured steel. Acta Materialia 2012; 60: 5933-5943. 


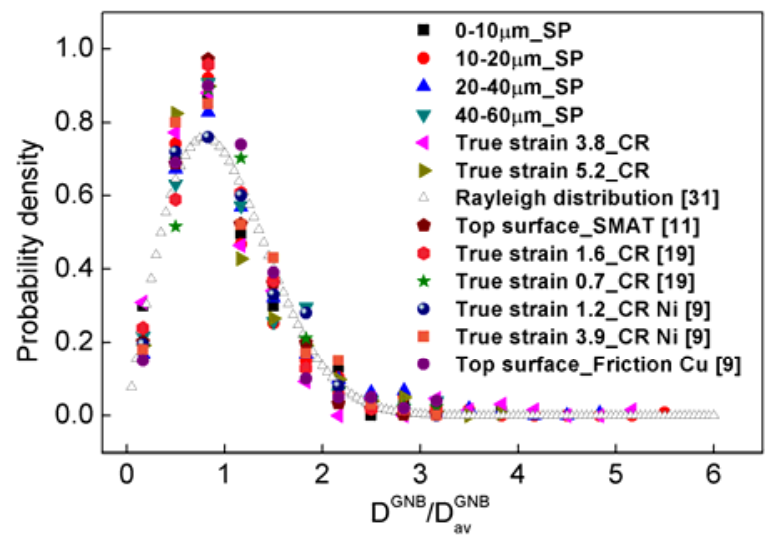

Figure 14. Probability density functions of the lamellar boundary spacing ( $D^{G N B}$ ) normalized by their respective average $\left(D_{a v}^{G N B}\right)$ for structures produced by shot peening (SP), cold rolling (CR) and friction. The experimental distributions are in good accordance with the theoretical Rayleigh distribution.

Please cite this paper as following

$X$ Zhang, $N$ Hansen, Y Gao, X Huang. Hall-Petch and dislocation strengthening in graded nanostructured steel. Acta Materialia 2012; 60: 5933-5943. 